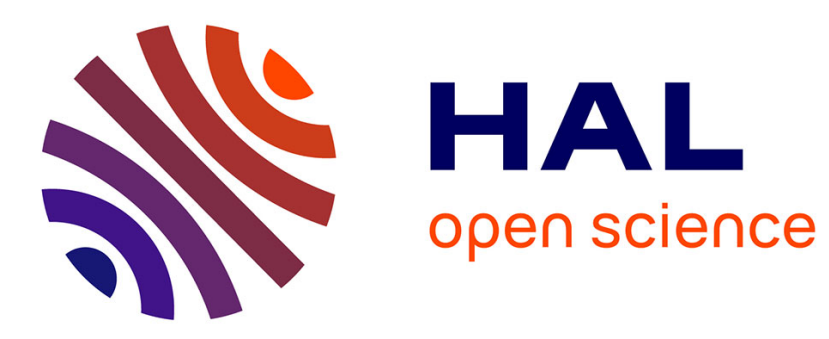

\title{
Fabrication of Nanopores Using the Controlled Dielectric Breakdown Technique
}

Nagel Amaguayo, Ariana Musello, Pablo Lopez, Lionel Trojman, Luis Miguel Prócel, Jose Bustamante

\section{- To cite this version:}

Nagel Amaguayo, Ariana Musello, Pablo Lopez, Lionel Trojman, Luis Miguel Prócel, et al.. Fabrication of Nanopores Using the Controlled Dielectric Breakdown Technique. 2021 IEEE Latin America Electron Devices Conference (LAEDC), Apr 2021, Mexico, France. 10.1109/LAEDC51812.2021.9437914 . hal-03238942

\section{HAL Id: hal-03238942 https://hal.science/hal-03238942}

Submitted on 27 May 2021

HAL is a multi-disciplinary open access archive for the deposit and dissemination of scientific research documents, whether they are published or not. The documents may come from teaching and research institutions in France or abroad, or from public or private research centers.
L'archive ouverte pluridisciplinaire HAL, est destinée au dépôt et à la diffusion de documents scientifiques de niveau recherche, publiés ou non, émanant des établissements d'enseignement et de recherche français ou étrangers, des laboratoires publics ou privés. 


\title{
Fabrication of Nanopores Using the Controlled Dielectric Breakdown Technique
}

\author{
Nagel Amaguayo*, Ariana Musello*, Pablo López ${ }^{\dagger}$, Lionel Trojman*‡, Luis Miguel Prócel* and José Bustamante ${ }^{\dagger \S}$ \\ *Instituto de Micro y Nanoelectrónica, Universidad San Francisco de Quito, Quito, Ecuador \\ ${ }^{\dagger}$ Departamento de Física, Universidad San Francisco de Quito, Quito, Ecuador \\ ${ }^{\ddagger}$ Laboratoire d’Informatique, Signal, Image, Télécommunication et Électronique, Institut Supérieur d'Électronique de Paris \\ $\S$ Department of Physics, McGill University, Montreal, Canada \\ Email: jabustamante@usfq.edu.ec
}

\begin{abstract}
Controlled dielectric breakdown is becoming the main solid-state nanopore fabrication technique worldwide. This paper presents the construction of a system for the fabrication of a single solid-state nanopore in a membrane using this technique. We include a basic introduction to nanopore theory. We also detail the building process of the low-cost equipment for nanopore fabrication, so that this paper can be used as a guide for building a similar system. Finally, we include the results of the creation of two nanopores and their characterization.
\end{abstract}

Index Terms-solid-state nanopores, controlled dielectric breakdown, silicon nitride, fluidic cell, leakage current, transmembrane, DNA \& RNA sensor, DAQ, ACC

\section{INTRODUCTION}

Solid-state nanopores are pores of nanometric scale fabricated on a thin inorganic material membrane such as silicon nitride $\mathrm{SiN}_{\mathrm{x}}$ [1]. These are frequently used for biomolecule characterization (DNA, RNA or proteins) by measuring ion currents and forces at the moment of their translocation [2]. Traditionally, solid-state nanopores are fabricated using transmission electron microscopy (TEM). This technique is based on sculpting the nanopore with a high energy electron beam concentrated on a specific point and it allows precision of $1 \mathrm{~nm}$ [3], but it is expensive.

H. Kwok et al. [3] demonstrated an alternative technique for solid-state nanopore fabrication through the controlled breakdown of a dielectric membrane in solution, subjecting it to a potential difference. This technology allows cheaper nanopore fabrication because of its simplicity: it does not require TEM and the equipment can be built easily in any lab. Besides, it offers sub-nanometric precision, comparable to TEM-based fabrication. This technique also offers plenty of advantages for biomolecule characterization: the nanopores are created directly in solution, allowing them to be wet and ready to use, and the fabrication system can be implemented in the characterization experiment [3]. This versatility allows the fabrication system to be combined with other techniques such as fluorescence microscopy [4], atomic force microscopy [5], fabrication of microfluidic channels [6], among others.

Controlled dielectric breakdown is becoming the main solidstate nanopore creation technique around the world [7].

\section{THEORETICAL FRAMEWORK}

The nanopores are fabricated in commercially available low stress $\mathrm{SiN}_{\mathrm{x}}$ TEM windows (Norcada, NT005X). Only one nanopore is created in each window where the $\mathrm{SiN}_{\mathrm{x}}$ presents more structural defects. This means that finding it and taking a picture with a TEM would be non viable.

For the dielectric breakdown fabrication process, the $\mathrm{SiN}_{\mathrm{x}}$ chip must be submerged in a $\mathrm{KCl}$ solution with a specific concentration and $\mathrm{pH}$. When a constant electric potential difference $\triangle V$ is applied across the thickness $L$ of the membrane, an electric field $E$ is generated inside of it [3]. This relation is defined with the equation $E=\frac{\Delta V}{L} . \triangle V$ is generated by a DC source through two electrodes in both sides of the membrane and the current flow is controlled with an ammeter with a minimum sensibility range within the order of nanoamperes (see Fig. 1). The potential difference across the nanopore can be approximated to the applied voltage $\triangle V$ [8].

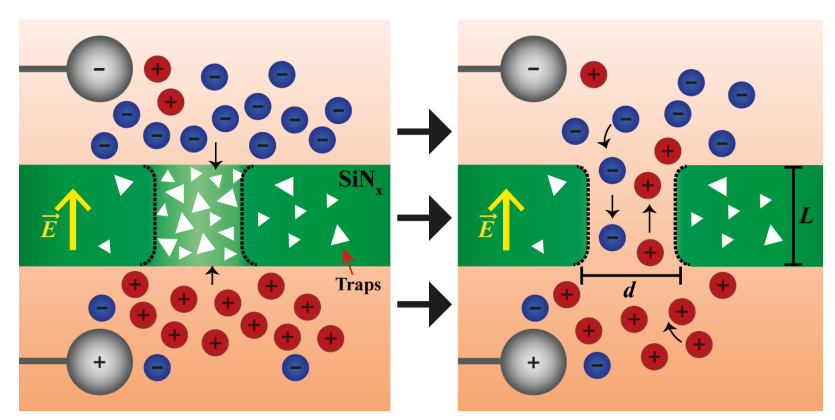

Fig. 1. Application of transmembrane electric potential, generation of electric field, leakage current and accumulation of traps (left), and creation of the nanopore (right) [3]).

The potential difference generates an accumulation of ions on the walls of the membrane, which generates leakage currents through the dielectric. The electrons go through the membrane by means of quantum tunneling assisted by traps (structural defects in the material). As seen in Fig. 1 (left), the induced electric field produces an accumulation of traps, which marks a highly localized path that eventually collapses (dielectric breakdown) creating the nanopore [3]. The nanopore and its dimensions can be seen in Fig. 1 (right). 
In order to estimate the diameter of the created nanopore, an equation for the resistance that it offers as a function of its diameter can be deduced. This resistance is the result of the internal cylindrical resistance of the pore (assuming the simplest geometrical approximation), and its access resistance. When $L>>d$, where $L$ is the pore longitude (membrane thickness) and $d$ is the pore diameter, $R_{\text {pore }}$ is dominant. Instead, when $L<<d, R_{a c c}$ is dominant [8].

On one hand, the internal cylindrical resistance $R_{\text {pore }}$ is modeled using (1) [8], where $A$ is the cylinder cross-sectional area, $L$ is its longitude, $d$ is its diameter, and $\sigma$ is the solution conductivity $(\mathrm{KCl})$ :

$$
R_{\text {pore }}=\frac{L}{\sigma \cdot A}=\frac{4 \cdot L}{\sigma \cdot \pi \cdot d^{2}}
$$

On the other hand, the access resistance $R_{a c c}$ is caused by the electric field $E$ lines that converge in the entrance of the pore [8]. According to Hille and Hall's model, this resistance is modeled as the resistance between a semi-spherical electrode in infinity and a flat disk-shaped electrode [8]. Equation (2) represents it [9].

$$
R_{a c c}=\frac{1}{\sigma \cdot d}
$$

The total nanopore resistance can be considered as the series configuration of $R_{\text {pore }}$ and $R_{a c c}$ [8], as seen in (3), and the inverse of $R_{\text {total }}$ indicates the nanopore conductance $G$.

$$
R_{\text {total }}=R_{\text {poro }}+R_{a c c}=\frac{1}{\sigma} \cdot\left(\frac{4 \cdot L}{\pi \cdot d^{2}}+\frac{1}{d}\right)=\frac{1}{G}
$$

The nanopore diameter $d$ can be cleared from (3). Therefore, if $G, L$ and $\sigma$ are known parameters, $d$ can be estimated. The LabView programs presented afterward perform this mathematical deduction to approximate the diameter of the fabricated nanopore.

\section{FABRICATION PROCESS AND INSTRUMENTATION}

The creation of solid-state nanopores requires a thorough process that calls for careful handling of chemical and electronic components.

\section{A. Setup of the $\operatorname{SiN}_{x}$ chip, fluidic cell and electrodes}

The setup of the $\mathrm{SiN}_{\mathrm{x}}$ chip, the fluidic cell and the $\mathrm{Ag} / \mathrm{AgCl}$ electrodes is based on [10].

1) SiN $_{x}$ chip and fluidic cell setup: In this project, a NORCADA chip (NT005X) was used with 30- $\mathrm{nm} \mathrm{SiN}_{\mathrm{x}}$ thickness, a $0.05-\mathrm{mm} \times 0.05-\mathrm{mm}$ window and $3-\mathrm{mm}$ diameter. The chip has to be located on a decontaminated slide, and a donutshaped gasket has to be located on each side. These gaskets are obtained from a silicone sheet 381- $\mu \mathrm{m}$ thick and the desired shape is achieved using a biopsy punch with the needed measurements; the cuts are made on a viscoelastic silicone surface with $1.5-\mathrm{cm}$ minimum thickness to avoid damage to the cutting instruments. Afterward, the gaskets are submerged in alcohol for decontamination.
The chip with the gaskets is later located in a PTFE or PEEK fluidic cell [3], which consists of two modules with built-in reservoirs that, when joined, maintain the chip and the gaskets tightly together between them. The gaskets seal the two faces of the $\operatorname{SiN}_{\mathrm{x}}$ chip to avoid any filtering of solutions between reservoirs [10]. These modules have to be submerged in nitric acid and then cleaned with deionized water to eliminate organic contaminants.

As mentioned, each module has a reservoir that allows solutions to be in contact with the chip [10]. The $\mathrm{KCl}$ solution is placed inside of them so that the chloride ions accumulate on the $\mathrm{SiN}_{\mathrm{x}}$ surface, thus generating a sufficiently large electric field to create leakage currents across the membrane [3]. Each one of the reservoirs is composed of one internal reservoir, in which solutions are injected, and another external one, through which they are extracted. In order to introduce the $\mathrm{KCl}$ solution so that it is fully in contact with the $\mathrm{SiN}_{\mathrm{x}}$ chip, a strict order of injection and extraction of alcohol, distilled water, and finally $\mathrm{KCl}$, has to be followed. A vacuum bell is also required to extract dissolved gases in solution. Details can be provided upon request.

In this project, $\mathrm{KCl}$ with $1 \mathrm{M}$ concentration and $\mathrm{pH} 10$ was used, as well as a potential difference of $15 \mathrm{~V}$. With these values, knowing that the $\mathrm{SiN}_{\mathrm{x}}$ used is $30-n m$ thick, and observing the data presented in [3], the nanopore creation time can be estimated at approximately 4000 seconds.

2) $\mathrm{Ag} / \mathrm{AgCl}$ electrode setup: To apply the potential difference through the chip, one silver electrode is submerged in the $\mathrm{KCl}$ solution of each reservoir [10]. The circuit in charge of applying the voltage can be connected to the electrodes by soldering rigid copper wires to their ends.

\section{B. Description of usage and connections of the Adaptation and Collection Card (ACC)}

In order to have complete control of the applied voltage and to know the current that flows through the membrane, a circuit is implemented that allows the voltages and currents to be read and digitized by a data acquisition card or DAQ (NI USB 6212) and visualized in a computer. This circuit, based on [3], has been denominated 'Adaptation and Collection Card' (ACC) and can be observed in Fig. 2. The ACC is connected to the DAQ through the ports OUTcontrol, INPUTcontrol and INPUTcheck.

As seen in [3], the ACC is powered with $\pm 20 \mathrm{~V}$ and consists of three stages. The first stage amplifies the voltage sent by the DAQ (OUTcontrol port in Fig. 2) with a non-inverting configuration with a gain of 2 using an AD820; the amplified voltage is applied to the membrane. The second stage measures the applied voltage and uses an inverting configuration with an AD820 and 1/100 scaling factor; the resulting voltage is sent to the DAQ (INPUTcheck port in Fig. 2) for monitoring in the corresponding program. The third stage measures the transmembrane current with a transimpedance amplifier topology that consists of an AD549 and a feedback resistance R5; the current is sent to the DAQ (INPUTcontrol port in Fig. 2). 


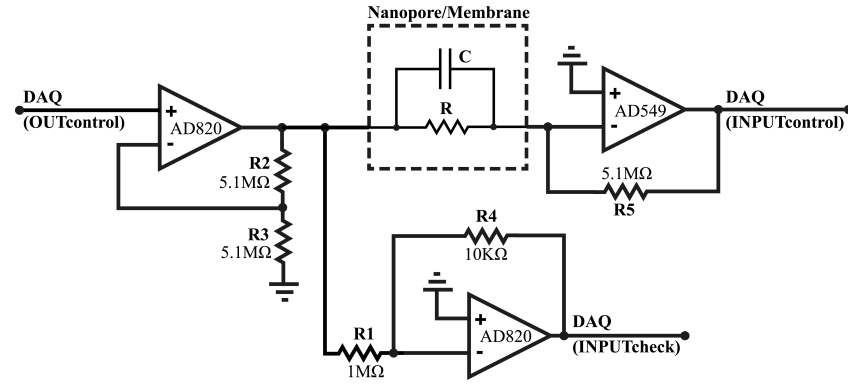

Fig. 2. Diagram of electronic connections of the ACC (based on [3]).

The connections between the ACC and the DAQ are available upon request.

\section{Faraday cage description}

If the transmembrane current is too low, electromagnetic noise is one of the greatest obstacles to obtaining accurate measurements. Consequently, a Faraday cage has to be constructed, inside of which the cell with the electrodes is placed [10]. A second Faraday cage should be used that contains the first cage and the ACC. The cabling between the DAQ and ACC is coaxial, which offers better protection to electromagnetic noise.

\section{Description of software}

The software programs were made using LabView, 2016 version, based on those provided by Vincent Tabard-Cossa.

1) D1. Nanopore creation program: Program D1 allows the solid-state nanopore creation. Its interface shows a graph of the transmembrane current and another one of the voltage between the $\mathrm{Ag} / \mathrm{AgCl}$ electrodes as a function of real time. The resistance R5 value has to be inserted, as well as the maximum limit for the transmembrane current (or 'cutoff' current), which must be larger than the leakage current. Once this cutoff current is reached, it means that a transmembrane current peak has occurred and, therefore, that a pore has been created; at this moment the program stops generating the potential difference through the electrodes, which halts the chip drilling. This program also has digital indicators of the value of the transmembrane current, which is obtained in the third stage of the ACC that enters through the INPUTcontrol port, and of the value of the voltage applied to the membrane verified in the second stage of the ACC that enters through the INPUTCheck port. The applied voltage value can be modified and manually turned off.

2) D2. Voltage sweep program: Program D2 performs a voltage sweep. The tendency followed by the transmembrane current data measured as a function of the varying applied voltage shows whether the $\mathrm{SiN}_{\mathrm{x}}$ membrane has undesired holes before the nanopore creation process, and whether the nanopore has been successfully created or not after such process. Generally, if there is a pore in the membrane, the tendency should be linear.
The interface allows to modify and insert the maximum voltage, minimum voltage, step size for the sweep, the resistance R5 value and the desired number of data per sample. It also shows a graph of the average values obtained in each iteration of transmembrane current as a function of the applied voltage. It indicates the applied voltage, the average verified applied voltage and the average transmembrane current in real time. The results are saved in a spreadsheet.

3) D3. Data analysis program: Program D3 opens the file generated by $\mathrm{D} 2$ after the nanopore creation process. The $\mathrm{KCl}$ conductivity $\sigma$ and $\operatorname{SiN}_{\mathrm{x}}$ membrane thickness $L$ values are entered. Next, a process of current value selection for negative and positive applied voltages is followed.

D3 performs a linear regression with the transmembrane current data as a function of applied voltage using the method of least squares to have an estimate of the slope of the sweep data. This slope corresponds to the conductance $G$ of the nanopore; both $G$ and its inverse $R_{\text {total }}$ are shown in the interface. Given that $\sigma, L$ and $G$ are now known by the program, it can calculate the nanopore diameter using (3), where $d$ has been cleared.

\section{RESUlTS}

The capacitance $C$ and resistance $R$ were measured with a BK PRECISION LCR Meter after filling the reservoirs with $\mathrm{KCl}$ solution and before subjecting the $\mathrm{SiN}_{\mathrm{x}}$ membrane to a $15 \mathrm{~V}$ potential difference. The results were $C=206.9 \mathrm{pF}$ and $R=1.869 M \Omega$. These high values confirmed that the membrane was in contact with the $\mathrm{KCl}$ solution.

Afterward, a voltage sweep from $-1 V$ to $1 V$ was performed with program D2 to know the state of the $\mathrm{SiN}_{\mathrm{x}}$ membrane. The resulting I-V curve, which shows the ideal behavior before drilling, can be seen in Fig. 3 .

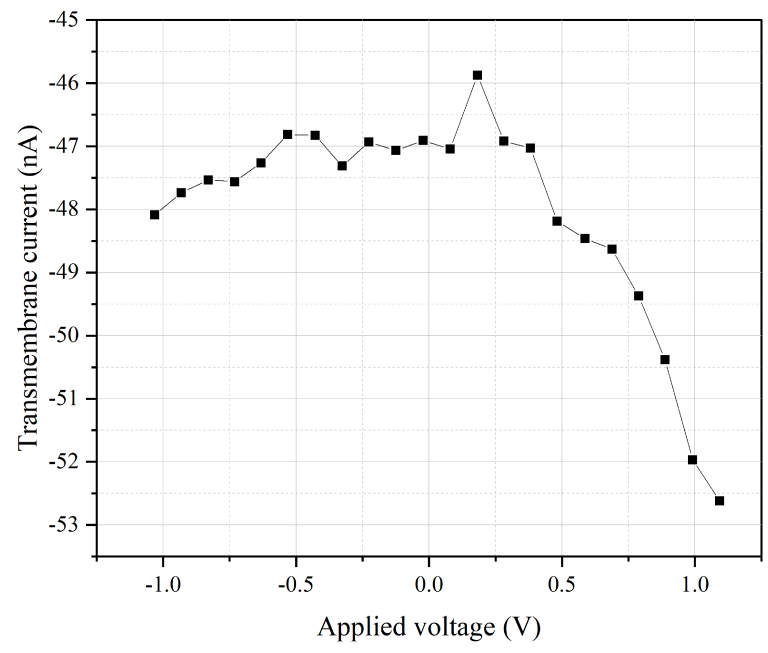

Fig. 3. Transmembrane current as a function of applied voltage before the drilling process.

Then, program D1 was run for 1 hour and 53 minutes with a potential difference of $15 \mathrm{~V}$. From the time when the experiment was initiated until $1 \mathrm{~h}: 52 \mathrm{~m}$, the measured transmembrane 
current as a function of time (see Fig. 4) presented a semistable behavior with an average value of $1.172 \mu \mathrm{A}$ and a maximum peak-to-peak noise of $2.333 \mu \mathrm{A}$.

As seen in Fig. 4, a sudden current peak was registered 1 hour and 52 minutes after the experiment was initiated, which indicates the creation of the pore [3]. After a short time, the polarization voltage was automatically turned off and the current across the nanopore stopped. This is visualized in the abrupt current drop in Fig. 4.

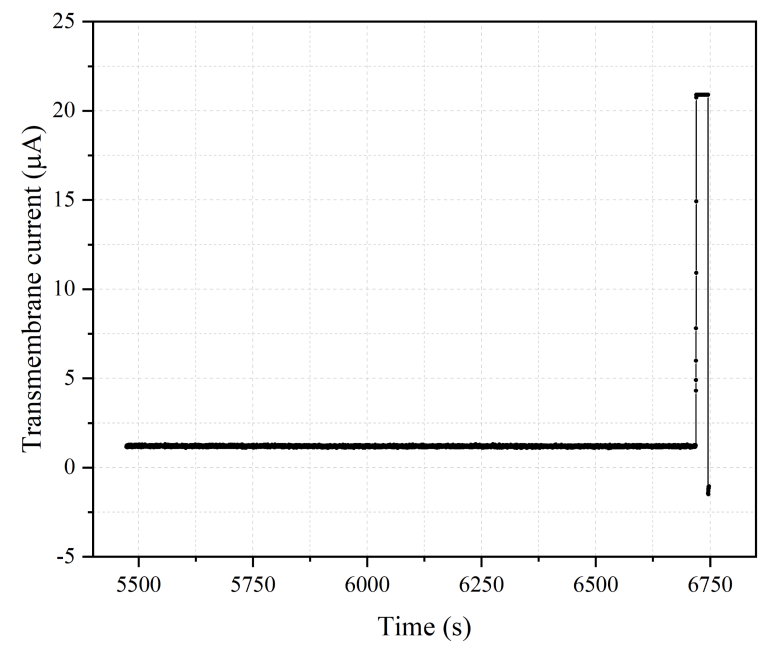

Fig. 4. Transmembrane current at $15 \mathrm{~V}$ as a function of time from $1 \mathrm{~h}: 31 \mathrm{~m}: 13 \mathrm{~s}$ with peak at $1 \mathrm{~h}: 52 \mathrm{~m}$

To confirm the creation of the nanopore, program D2 was run once again to perform a voltage sweep from $-1 \mathrm{~V}$ to $1 \mathrm{~V}$. The measured transmembrane current as a function of applied voltage is shown in Fig. 5.

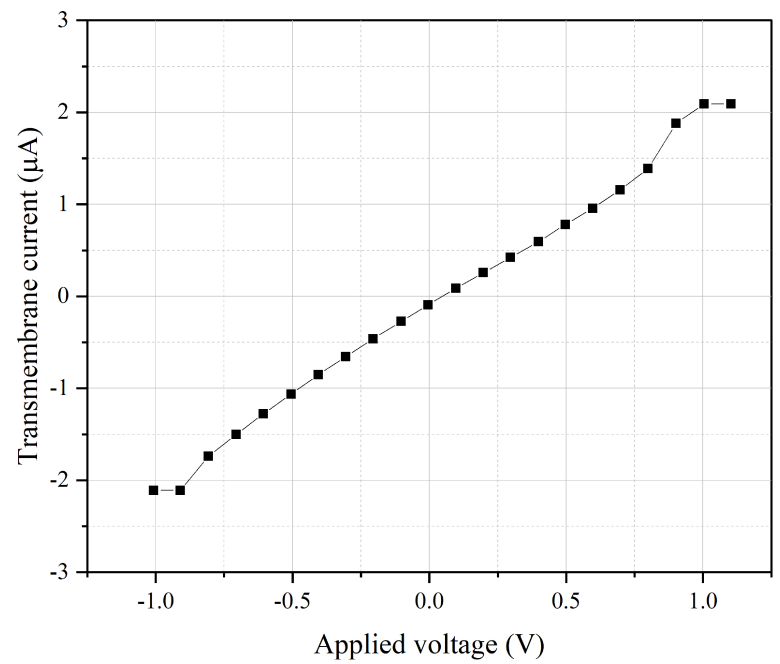

Fig. 5. Transmembrane current as a function of applied voltage after drilling process.

As seen in Fig. 5, the I-V curve has a linear behavior that is coherent with the fact that the membrane has a pore.
Finally, program D3 was run to estimate the diameter of the created nanopore, for which the $\mathrm{KCl}$ solution conductivity of $114.5 \mathrm{~S} / \mathrm{m}$ and the $\mathrm{SiN}_{\mathrm{x}}$ thickness of $30-\mathrm{nm}$ had to be entered. For the negative part of the applied voltage domain, a $2.12 \pm 0.14 \mu S$ slope was obtained (conductance of the nanopore), and an approximate diameter of $37.4 \pm 1.0 \mathrm{~nm}$. For the positive side of the voltage domain, a $2.14 \pm 0.24 \mu S$ slope (conductance) was obtained and a $37.7 \pm 1.8 \mathrm{~nm}$ diameter. In average, the nanopore is estimated to have a $37.5 \pm 1.0 \mathrm{~nm}$ diameter.

\section{CONCLUSIONS}

The construction of a system for solid-state nanopores creation using the controlled dielectric breakdown technique [3] was presented in this paper. The setup of the $\operatorname{SiN}_{x}$ membrane and the fluidic cell, the functioning of the ACC, and the software used were described. Following the given outlines, a nanopore was successfully created with a diameter of $37.5 \pm 1.0 \mathrm{~nm}$, which behaves like a 30- $\mathrm{nm}$ long cylindrical resistance.

Regarding the nanopore creation time, approximately 1 hour and 7 minutes of voltage submission were estimated based on the potential drop used and solution and membrane characteristics. However, the dielectric breakdown of the membrane was registered after 1 hour and 52 minutes. This extension in time is consistent with the variability proper to the nanopore creation process.

It is worth mentioning that the experiment was performed one more time. Another nanopore was created with an approximate $30.4 \mathrm{~nm}$ diameter, based on an approximate diameter of $31.6 \mathrm{~nm}$ in the positive voltage domain and of $29.3 \mathrm{~nm}$ for the negative voltage domain.

\section{ACKNOWLEDGMENTS}

Authors thank V. Tabard-Cossa and M. Waugh for their generous contribution with materials, and M. Navarrete and G. Cuesta for the Faraday Cage. This work was financed by Instituto de Micro y Nanoelectrónica (IMNE) of Universidad San Francisco de Quito, Ecuador.

\section{REFERENCES}

[1] T. Gibb and M. Ayub, "Solid-state nanopore fabrication," in Engineered Nanopores for Bioanalytical Applications. Elsevier Inc., 2013, pp. 121-140. [Online]. Available: https://doi.org/10.1016/B978-1-43773473-7.00005-4

[2] C. Dekker, "Solid-state nanopores," Nature Nanotechnology, vol. 2, no. 4, pp. 209-215, Mar. 2007. [Online]. Available: https://doi.org/10.1038/nnano.2007.27

[3] H. Kwok, K. Briggs, and V. Tabard-Cossa, "Nanopore fabrication by controlled dielectric breakdown," PLOS ONE, vol. 9, no. 3, Mar. 2014 [Online]. Available: https://doi.org/10.1371/journal.pone.0092880

[4] Z. Roelen, J. Bustamente, A. Carlsen, A. Baker-Murray, and V. Tabard-Cossa, "Instrumentation for low noise nanopore-based ionic current recording under laser illumination," Review of Scientific Instruments, vol. 89, no. 015007, Jan. 2018. [Online]. Available: https://doi.org/10.1063/1.5006262

[5] T. St-Denis, K. Yazda, X. Capaldi, J. Bustamante, M. Safari, Y. Miyahara, Y. Zhang, P. Grutter, and W. Reisner, "An apparatus based on an atomic force microscope for implementing tip-controlled local breakdown," Review of Scientific Instruments, vol. 90, no. 123703, Dec. 2019. [Online]. Available: https://doi.org/10.1063/1.5129665 
[6] R. Tahvildari, E. Beamish, V. Tabard-Cossa, and M. Godin, "Integrating nanopore sensors within microfluidic channel arrays using controlled breakdown," Lab Chip, vol. 15, pp. 1407-1411, Jan. 2015. [Online]. Available: https://doi.org/10.1039/C4LC01366B

[7] M. Waugh, K. Briggs, D. Gunn, M. Gibeault, S. King, Q. Ingram, A. Jimenez, S. Berryman, D. Lomovtsev, L. Andrzejewski, and V. Tabard-Cossa, "Solid-state nanopore fabrication by automated controlled breakdown," Nature Protocols, vol. 15, pp. 122-143, Jan. 2020. [Online]. Available: https://doi.org/10.1038/s41596-019-0255-2

[8] T. Albrecht, T. Gibb, and P. Nuttall, "Ion transport in nanopores," in Engineered Nanopores for Bioanalytical Applications. Elsevier Inc., 2013, pp. 1-30. [Online]. Available: https://doi.org/10.1016/B978-14377-3473-7.00001-7

[9] J. Hall, "Access resistance of a small circular pore," Journal of General Physiology, vol. 66, no. 4, pp. 531-532, 1975. [Online]. Available: https://doi.org/10.1085/jgp.66.4.531

[10] V. Tabard-Cossa, "Instrumentation for low-noise high-bandwidth nanopore recording," in Engineered Nanopores for Bioanalytical Applications. Elsevier Inc., 2013, pp. 59-93. [Online]. Available: https://doi.org/10.1016/B978-1-4377-3473-7.00003-0 